\title{
Spondyloarthropathy: A critical management analysis
}

\section{Shiva Shankar Jha}

Director and Head, Dept. of Orthopaedics, Mahavir Vaatsalya Aspatal, Patron \& Founder President, Indian Orthopaedic Rheumatology Association Vice Secretary General, Asia-Pacific Society for Foot \& Ankle Surgery, Past President, Indian Foot \& Ankle Society, Patna, Bihar, India

\section{*Corresponding Author: Shiva Shankar Jha}

Email: drssjha@gmail.com

\begin{abstract}
Spondyloarthropathy, a group of overlapping disorders of chronic inflammatory diseases of autoimmune nature has undergone critical changes in its management, specially with introduction of newer biologics and targeted synthetic DMARDs. Secukinumab and Tofacitinib are newer additions to proper management targeting various cytokines. Cost being an important factor in developing world, conventional synthetic DMARDs are being advocated to be used in situations where patient can not afford the treatment with biologics / small molecules i.e. JAK Inhibitors. It is heartening to know that methotrexate can achieve $20 \%$ remission in psoriatic arthritis almost equivalent to some biologics. Drug antibody is also a challenging problem in management with biologics.
\end{abstract}

Keywords: Biologic, DMARDs, Secukinumab, Tofacitinib, JAK Inhibitors, Cost.

\section{Introduction}

Spondyloarthropathy cannotes sero-negative spondyloarthropathy implying absence of rheumatoid factor. SpA is a group of overlapping disorders of chronic inflammatory diseases of autoimmune nature sharing certain clinical features and common genetic associations with HLA-B27.

Broadly it is grouped as axial spondyloarthropathy and peripheral arthropathy.
Among axial-spondyloarthropathy, initially it presents as non-radiographic spondyloarthropathy (nr-axSpA) which finally progresses to ankylosing spondylitis in a span of five to ten years, whereas in some cases it might continue to remain non-radiographic $\mathrm{SpA}$. This progression is evident overtime in the following tables in adult onset and juvenile onset:-

\section{SpA: Progression of SpA overtime 2}

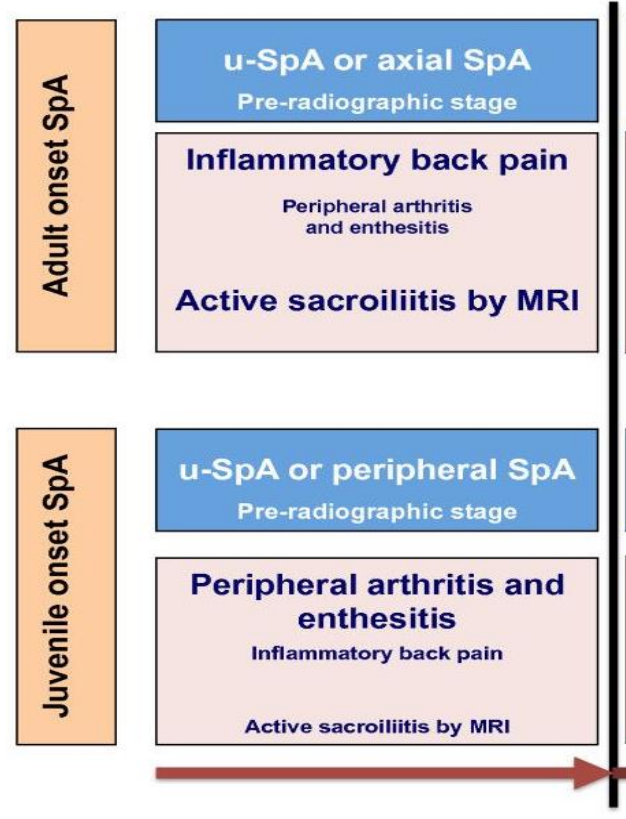

Less than 5 years

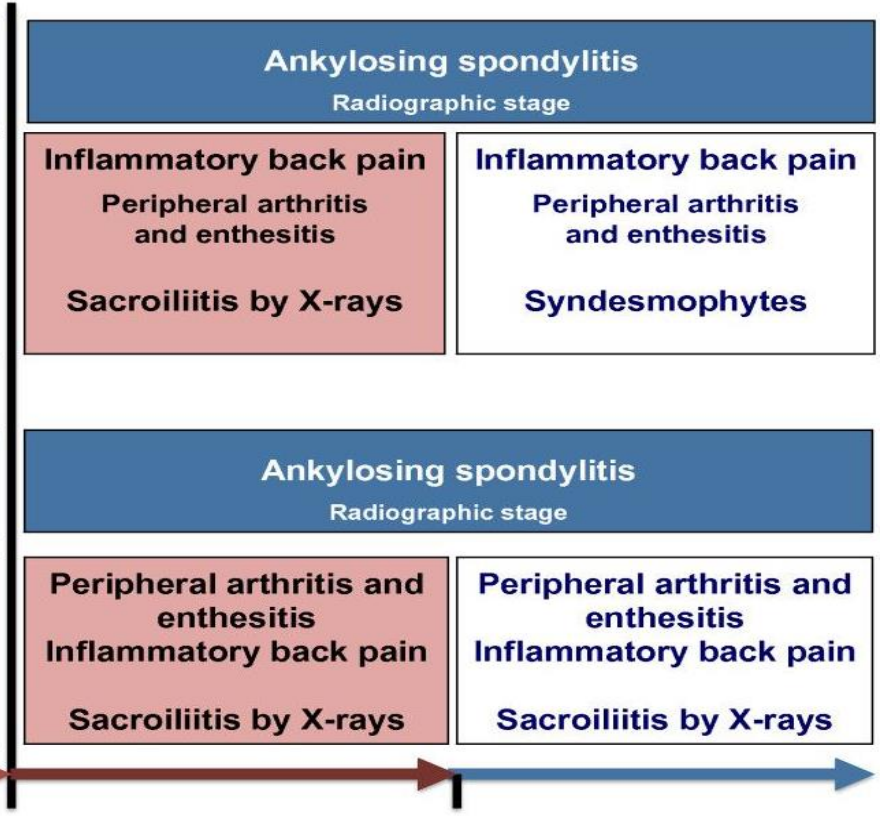

5 to 10 years
More than 10 years

Transition of AxSpA into as? When

Evolution of the disease process from AxSpA into ankylosing spondylitis is marked only when ankylosis 
typical of ankylosing spondylitis appears over a period of more than ten years.

The peripheral spondyloarthropathy (A certain pattern of peripheral joint involvement, usually asymmetric monoarthritis or oligoarthritis affecting major joints of lower extremities) encompasses psoriatic arthropathy, associated with inflammatory bowel disorder (i.e. Crohn's disease and ulcerative colitis), associated with anterior uveitis, reactive arthritis (Reiter's Disease). Sometimes to start with, it can not be differentiated into a particular pattern and hence, is called undifferentiated spondyloarthritis. Similar presentation in children is aptly coined as juvenile spondyloarthropathy. Enthesitis and dactylitis are commonly associated extra-articular manifestations in this group, apart from axial involvement.

In patients younger than 45 years presenting with $\geq 3$ months of back pain ASAS criteria classifies them for diagnosis of SpA. Patient has to be submitted for MRI of sacroiliac joint. Active (acute) inflammation therein suggesting presence of sacroiliits or presence of a definite radiographic sacroiliitis showing one or more of the eleven $\mathrm{SpA}$ features is diagnostic of SpA. Conversely, in presence of HLA-B27 positive, two or more SpA features out of the eleven are also diagnostic of $\mathrm{SpA} .^{3}$

\title{
ASAS criteria for axSpA
}

In patients with $\geq 3$ months back pain and age of onset $<45$ years

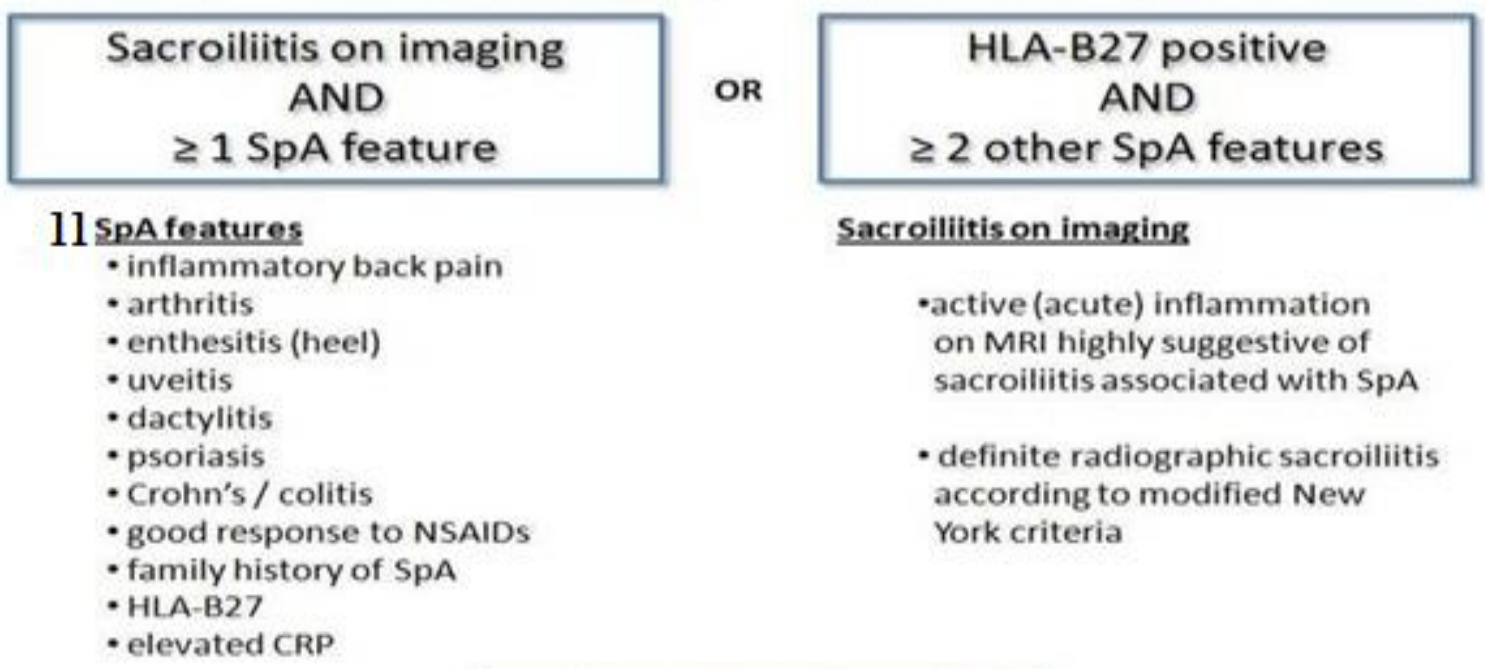

Sensitivity $82.9 \% \quad$ Specificity $84.4 \%$

The following modified New York criteria for classification of ankylosing spondylitis has been replaced with the above ASAS criteria.

\author{
Modified New York Criteria for classification of Ankylosing Spondylitis ${ }^{4}$ \\ Clinical \\ Low back pain and stiffness for more than 3 months that improves with exercise but is not relieved by rest. \\ Limitation of motion of the lumbar spine in the sagittal and frontal planes. \\ Limitation of chest expansion to $2.5 \mathrm{~cm}(1 \mathrm{inch})$ or less, measured at the level of the fourth intercostal space.
}

\section{Radiographic}

Sacroiliitis: Unilateral grade 3 (sclerosis and erosions of the joint margins) or grade 4 (fusion across the joint).

Bilateral grade 2 (sclerosis of joint margins) to 4.

Definite ankylosing spondylitis: unilateral grade 3 or 4, or bilateral grade 2 to 4 sacroiliitis and any of the clinical criterion. 


\section{ASAS criteria for Peripheral SpA}

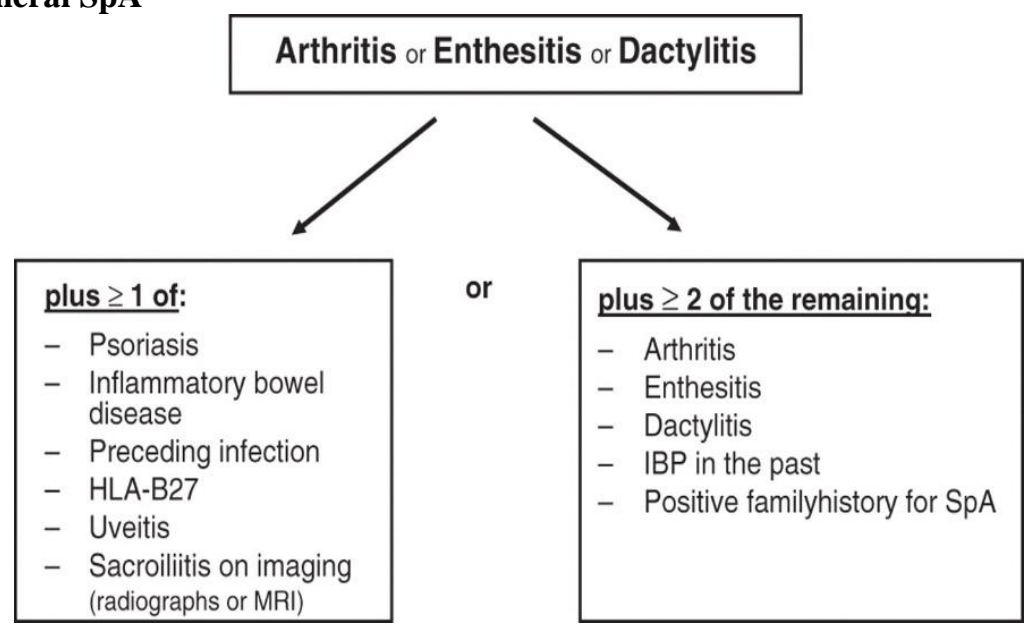

\section{MRI for diagnosis of SpA}

The introduction of MRI of the sacroiliac joints (SIJs) has led to a major shift in recognition of the disorder. MRI detects the initial inflammatory processes, in particular osteitis depicted by bone marrow oedema, even in patients who have not yet developed structural lesions. Interpretation of MRI lesions in daily practice depends on the clinical context

\section{Characteristic lesions in Spine and SIJs depicted by MRI ${ }^{5}$}

\begin{tabular}{|c|c|}
\hline Inflammatory changes & Structural changes \\
\hline \multicolumn{2}{|c|}{ SIJs } \\
\hline $\begin{array}{l}\text { Sacroiliitis-bone marrow edema/osteitis in one } \\
\text { or both part of the sacroiliac joint (iliac or sacral) }\end{array}$ & Subchondral sclerosis \\
\hline Synovitis & Erosions \\
\hline Capsulitis & $\begin{array}{l}\text { Backfill/subchondral fat metaplasia } \\
\text { Bony bridges }\end{array}$ \\
\hline Enthesitis & Ankylosis \\
\hline \multicolumn{2}{|c|}{ Spine } \\
\hline $\begin{array}{l}\text { Anterior/posterior spondylitis-bone marrow } \\
\text { edema/osteitis mainly in the vertebral corners }\end{array}$ & Fat metaplasia \\
\hline Spondylodiscitis & Erosions \\
\hline Arthritis of costovertebral joints & Syndesmophytes \\
\hline Facet joints arthritis & Ankylosis \\
\hline Enthesitis of spinal ligaments & \\
\hline
\end{tabular}

\section{Treatment options of SpA including biologics}

Treatment aims at potential deceleration of the disease process resulting into control symptoms and inflammation thereby maintaining health-related quality of life. Prevention and arrest of structural progression should ultimately result into remission or low-disease activity.

\section{NSAIDs}

NSAIDs constitute first-line therapy for active ankylosing spondylitis (AS). Continuous use of NSAIDs (2 NSAIDs for 3 months) is generally accepted but its continued use is controversial because of the apprehension of its unwarranted end organ complications ${ }^{6}$. Hence, in stable disease, ondemand NSAIDs is to be preferred.
NSAIDs have shown satisfactory evidence of symptom control and functional improvement but there are only some evidences in favour of achieving slower radiographic progression on continuous use.

\section{Biologics}

Introduction of biologics have revolutionized the management of spondyloarthropathy. This armamentarium has considerable expansion of ability to control the disease by specifically targeting the immune system. It considerably avoids other end organ toxicity. It provides satisfactory evidence based symptom control and functional improvement. There is growing body of evidence regarding 
slowing or stopping radiographic progression on its longterm use.

\section{The available biologic armamentarium ${ }^{7}$}

a. Targeting TNF $\alpha$ cytokine-Infliximab, Etanercept, Adalimumab, Golimumab and Certolizumab.

b. Targeting IL 17 cytokine- Secukinumab

c. Targeting IL 12 and IL 23 cytokine- Ustekinumab

d. JAK1 inhibitors-

Targeting JAK1 and JAK 3- Tofacitinib

Targeting JAK1 and JAK 2- Baricitinib

Targeting PDE4 - Apremilast

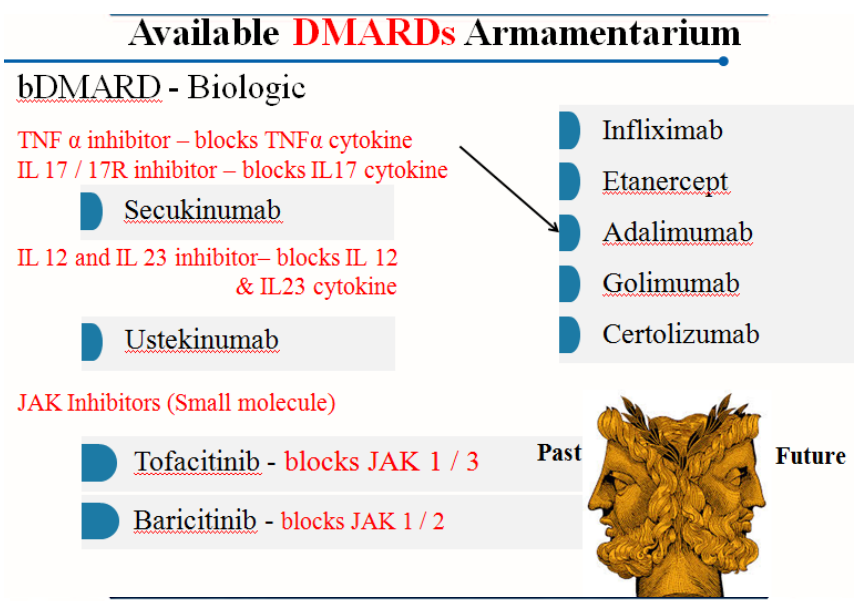

Currently available treatment options - TNF $\alpha$ Inhibitor (TNFi)

Second line therapy in treatment of Spondyloarthritis

TNF- $\alpha$ is an important inflammatory mediator, its inhibition facilitates the development of biological agents

TNF- $\alpha$ inhibitors are effective for treatment of not only in advanced AS but also in early stage of AS

Early use of TNF- $\alpha$ inhibitors has been recommended for patients diagnosed

with AS and treated with more than two NSAIDs over 3 months

\section{Secukinumab: Clinical considerations}

Secukinumab is a fully human anti-interleuking IL-17A monoclonal antibody. It shows sustained improvements in signs and symptoms of ankylosing spondylitis with a low rate of structural radiographic progression. It has sustained efficacy through a total 3 years of treatment. Sings and symptoms of AS (assessed by ASAS20) gets lower at week 6 and is sustained at week 28 through 2 years along with decreased inflammation as assessed by MRI. ${ }^{8,9}$

\section{Targeted synthetic DMARD (tsDMARD)}

These oral small Molecule-JAK inhibitors are chemically more related to traditional methotrexate than to biological DMARD. They act like biological DMARDs in their mode of action of suppression of cytokines. It targets multiple cytokines and inhibit intracellular signaling of cytokines and growth factors, whereas $\mathrm{TNF} \alpha$ inhibitors target a single cytokine and work within extra cellular space targeting cell surface receptors. These small molecules also target increased biologic disease activity across multiple pathways. Their onset of response occurs within two weeks and efficacy is maintained up to five years.

Heralding the transition to new era of treatment with small molecule, first JAK inhibitor, Tofacitinib has been approved by USA FDA since November 2012 and is recommended for use in spondyloarthropathy.

Candidates of spondyloarthropathy requiring biologic treatment ${ }^{10-11}$

1. Patients for whom conventional therapy with nonsteroidal anti-inflammatory drugs (NSAIDs) has failed.

2. When two different NSAIDs aren't much effective and helping the patient.

3. NSAIDs causing GI problems or other medical conditions and patients still have high pain and stiffness.

4. Disease having a big impact on patient's life or might be affecting work, family life etc.

5. Non Responder / Failure of 1st line csDMARDs in peripheral SpA.

\section{ACR Recommendation ${ }^{12}$}

\section{Biological Therapies for Spondyloarthritis}

From time-to-time recommendations for biological therapies have been changing but the most current ACR recommendations have finally come to a conclusive set of recommendations.

As a first step, the disease activity is to be assessed whether the axial disease is active AS or stable AS. The active disease is further looked for additional disease manifestations and presence of isolated sacroiliitis or enthesisits is taken note off.

\section{Therapies for Spondyloarthritis}

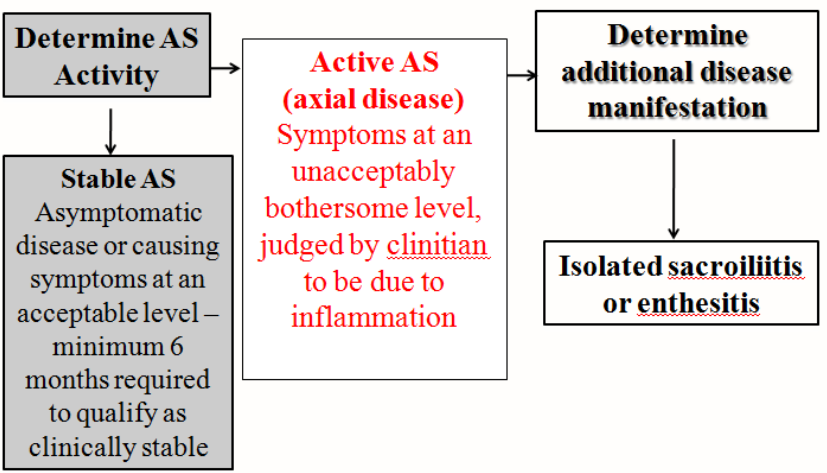

The recommendation for active AS has been put forward into three lines of therapy as under:-

First line of therapy are NSAIDs. In peripheral SpA not improving on NSAIDs, local infilteration of glucocorticoid is conditionally recommended if upto two joints are involved and additionally sulfasalazine is preferred over methotrexate. Leflunomide, Apremilast, Thalidomide and Pamidronate are conditionally recommended against their 
use. There are strong recommendations against use of systemic glucocorticoids. For isolated sacroiliitis or enthesitis, local glucocorticoid injection is conditionally recommended (avoid glucocorticoid injection at achilles, patellar, and quadriceps entheses) but conditional recommendation against use of glucocorticoid parenteral injection is there.

Therapies for Spondyloarthritis

\section{Colour coding of subsequent recommendations}

\begin{tabular}{|c|c|c|}
\hline Green & & Strongly recommend \\
\hline Light Green & $\square$ & Conditionally recommend \\
\hline Purple & L & Conditionally recommend against \\
\hline Red & & Strongly recommend against \\
\hline
\end{tabular}

Bracketed numbers refer to recommendation number of ACR

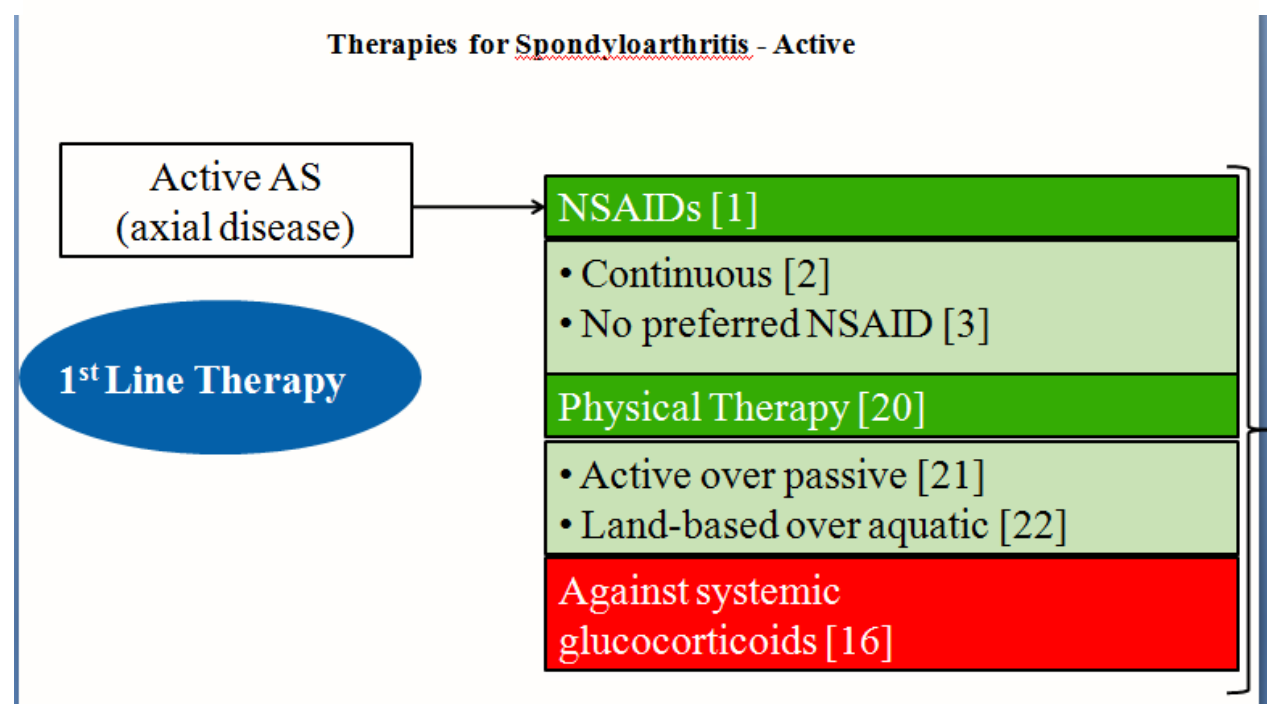

Therapies for Spondyloarthritis - Active

\begin{tabular}{|c|c|}
\hline $\begin{array}{c}\text { Active AS } \\
\text { (axial disease) }\end{array}$ & $\begin{array}{l}\text { Determine additional disease } \\
\text { manifestation }\end{array}$ \\
\hline $1^{\text {st }}$ Line Ther & $\begin{array}{l}\text { Peripheral-predominant arthritis } \\
\text { despite NSAIDs }\end{array}$ \\
\hline Conditionally recommended & $\begin{array}{l}\text { Local GC if } \leq 2 \text { joints [19] SSZ [7] } \\
\text { - SSZ over MTX [4] }\end{array}$ \\
\hline Conditionally recommend against & $\begin{array}{l}\text { Against Lefulonomide, APR, Thalidomide, } \\
\text { Pamidronate [4] }\end{array}$ \\
\hline
\end{tabular}


Therapies for Spondyloarthritis - Active

\begin{tabular}{|c|c|}
\hline $\begin{array}{l}\text { Determine additional } \\
\text { disease manifestation }\end{array}$ & \begin{tabular}{|c|} 
Isolated sacroiliitis or enthesitis \\
\hline NSAIDs [17, 18] Cond. Recom.
\end{tabular} \\
$\qquad \begin{array}{l}\text { Isolated sacroiliitis or enthesitis } \\
\text { despite NSAIDs }\end{array}$ \\
Conditionally recommended & $\begin{array}{l}\text { Local GC [17, 18] } \\
\text { Conditionally recommend against }\end{array}$ \\
& $\begin{array}{l}\text { Avoid Achilles, patellar, and } \\
\text { quadriceps entheses GC injections } \\
{[18]}\end{array}$ \\
&
\end{tabular}

Second line of therapy is exclusively TNF $\alpha$ inhibitors. Conditionally recommended biologic is Secukinumab over Tofacitinib. In case of AS with IBD or uveitis, the conditionally recommended biologic is monoclonal TNF $\alpha$ inhibitor. Spinal or pelvic MRI is recommended if AS is present with unclear activity on biologic.

\section{Biological Therapies for Spondyloarthritis - Active}
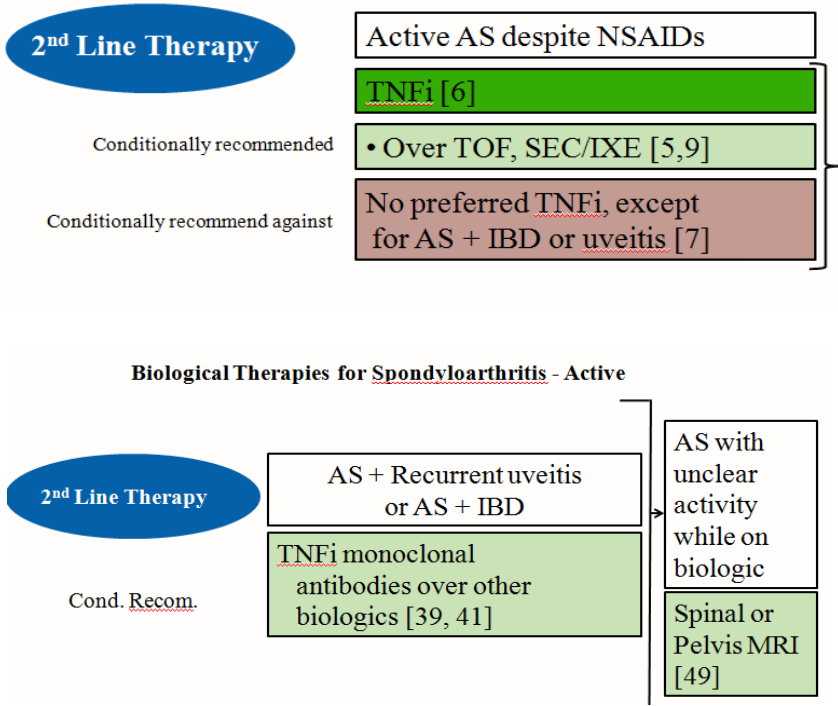

\section{$3^{\text {rd }}$ Line Therapy}

Cond. Recom.

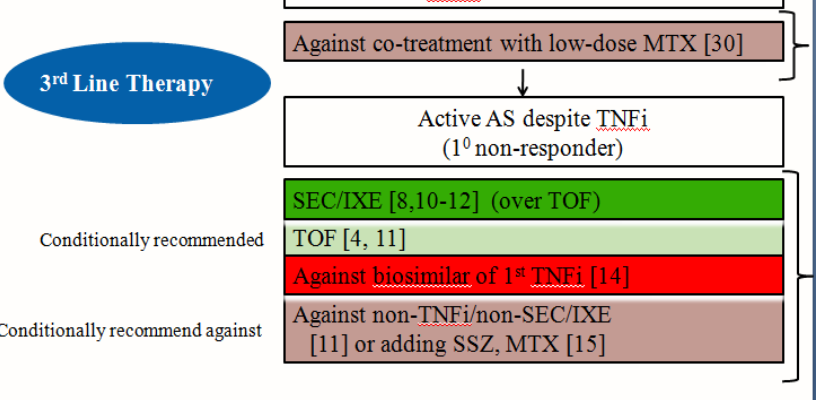

Biological Therapies for Spondyloarthritis - Active

\begin{tabular}{|c|}
\hline Active AS on TNFi \\
\hline $\begin{array}{c}\text { Against co-treatment with low-dose MTX } \\
{[30]}\end{array}$ \\
\hline $\begin{array}{c}\text { Active AS despite TNFi } \\
\left(2^{0} \text { non-responder }\right)\end{array}$ \\
\hline Alternative TNFi [13] \\
\hline Against biosimilar of $1^{\text {st }}$ TNFi [14] \\
\hline $\begin{array}{c}\text { Against non-TNFi/non-SEC/IXE } \\
\text { [13] or adding SSZ, MTX 15] }\end{array}$ \\
\hline
\end{tabular}

Therapies for Spondvloarthritis - Stable

Stable AS (axial disease)

NSAIDs
- On-demand (23) Cond. Recom.

Physical Therapy (29) Ixekizumab are recommended over Tofacitinib. Tofacitinib is conditionally recommended. There is conditional recommendation against non-TNFi/non-SEC/IXE or adding SSZ, MTX. There are strong recommendation against biosimilar of 1 st TNF $\alpha$ inhibitor. 
Biological Therapies for Spondvloarthritis - Stable

\begin{tabular}{l|}
\hline Physical Therapy (29) \\
Stable AS on biologic \\
$\begin{array}{l}\text { Against discontinuation of biologic (26) } \\
\text { Against biologic tapering as a standard approach (27) }\end{array}$ \\
\hline
\end{tabular}

Biological Therapies for Spondyloarthritis - Stable

\begin{tabular}{|c|}
\hline Physical Therapy (29) \\
\hline Stable AS on TNFi + NSAID \\
\hline Continue TNFi alone; stop NSAID (24) \\
\hline
\end{tabular}

Biological Therapies for Spondyloarthritis - Stable

\begin{tabular}{|c|}
\hline Physical Therapy (29) \\
\hline$\downarrow$ \\
\hline Stable AS on TNFi + oral small molecule \\
\hline Continue TNFi alone; stop csARD (25) \\
\hline
\end{tabular}

Biological Therapies for Spondyloarthritis - Stable

\begin{tabular}{|l|}
\hline Physical Therapy (29) \\
Stable AS on TNFi \\
$\begin{array}{l}\text { If on originator TNFi, do not switch to biosimilar TNFi } \\
\text { as a standard approach (28) }\end{array}$ \\
Against co-treatment with low-dose MTX (30) \\
\hline
\end{tabular}

Therapies for Spondyloarthritis - Stable

Determine additional disease manifestation

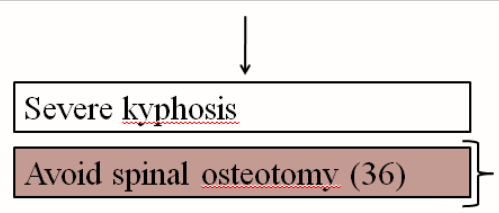

Therapies for Spondyloarthritis - Stable

Spinal fusion or advanced osteoporosis

Avoid spinal manipulation (34)

Advanced hip arthritis

Total hip arthroplasty (35)

Active \& Stable AS

Conditionally Recommend

General Adjunctive Management: at all stages

1. Unsupervised back exercises [31]

2. Formal group or individual self-management education [33]

3. Fall evaluation/counselling [32]

4. Monitor using validated AS disease activity measures, \& CRP or ESR $[42,43]$ regularly

Active AS - Physical Therapy \& Miscellaneous

Conditionally Recommend against

General Adjunctive Management:

1. Against using treat-to-target strategy with target of ASDAS $<1.3$ or 2.1 over strategy based on provider assessment (44);

2. Against obtaining repeat spine radiographs at a scheduled interval (51)

Stable AS

Conditionally Recommend against

\section{General Adjunctive Management:}

1. Against obtaining spinal or pelvis MRI to confirm inactivity

\section{Dose of biologics in $\mathrm{AS} \& \operatorname{Ps} \mathrm{A}^{13-17}$}

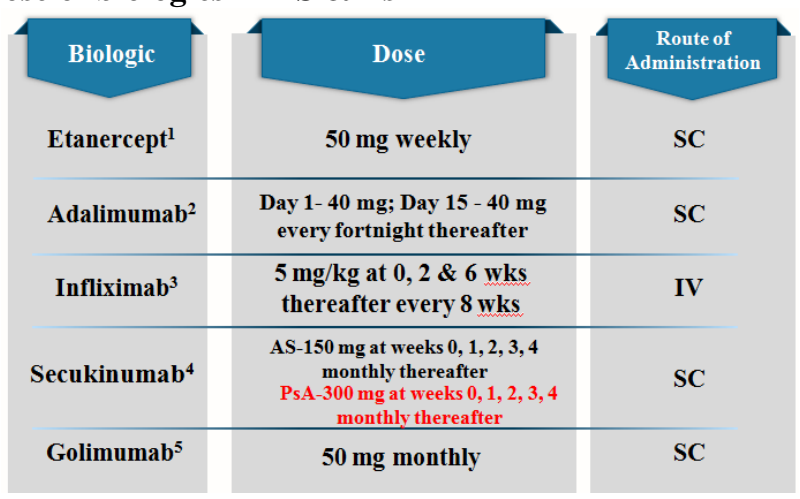




\section{Investigations to be done before instituting biologics}

\begin{tabular}{|c|c|}
\hline \multicolumn{2}{|c|}{ RA Factor-negative } \\
\hline CBC, ESR, CRP & 6 SETS \\
\hline $\begin{array}{c}\text { Mantoux test, Quantiferon } \\
\text { gold test (IGRA) }\end{array}$ & $\begin{array}{c}\text { HIV, HBsAg } / \text { HBcAg, HCV, } \\
\text { HBC core total antibody }\end{array}$ \\
\hline X-Ray chest, ECG & Blood sugars (fasting, PP) \\
\hline LFT & Routine urine ex. \\
\hline S Creatinine & Routine Stool ex. \\
\hline ANA & UPT (females) \\
\hline
\end{tabular}

Types of lesions considered in the study ${ }^{18}$

Treated with anti-TNF agents

Long term observational study using MRI and conventional radiography

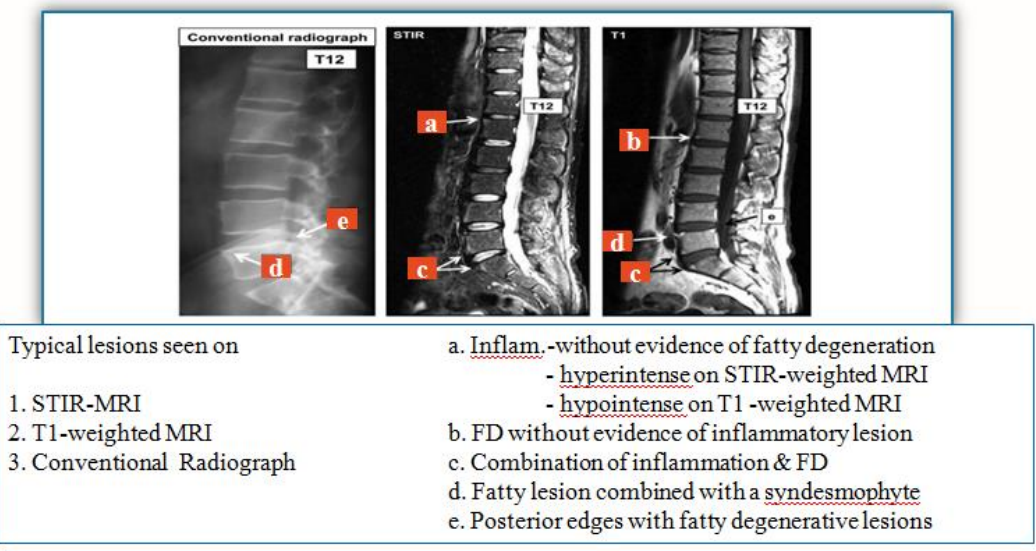

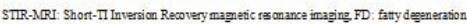

\section{Which of these spinal lesions progress to new bone formation? ${ }^{18}$}

Treated with anti-TNF agents

Long term observational study using MRI and conventional radiography

\begin{tabular}{|c|c|c|c|c|}
\hline \multicolumn{2}{|c|}{ Baseline } & \multicolumn{2}{|c|}{ At 2 years } & \multirow{2}{*}{ 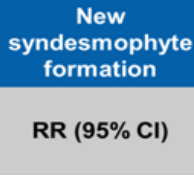 } \\
\hline $\begin{array}{l}\text { Inflammati } \\
\text { on }\end{array}$ & $\begin{array}{c}\text { Fatty } \\
\text { degeneratio } \\
\mathbf{n}\end{array}$ & Inflammation & $\begin{array}{c}\text { Fatty } \\
\text { degeneration }\end{array}$ & \\
\hline No & No & No & Yes & $2.4^{\star}(1.1$ to 5.2$)$ \\
\hline Yes & No & No & Yes & $0.8(0.2$ to 4.4$)$ \\
\hline No & Yes & No & Yes & 1.5 (0.6 to 3.8$)$ \\
\hline Yes & Yes & No & Yes & $3.3^{*}(1.3$ to 8.1$)$ \\
\hline
\end{tabular}

Of the VEs with inflammation at baseline, $>70 \%$ resolved completely, $28.8 \%$ turned into FD after 2 years, but only 1 syndesmophyte developed within 5 years

RR: Relative Risk VE; vertebal edges 
Interesting points for consideration ${ }^{19}$

\title{
REMISSION
}

\author{
in axial- $\mathrm{SpA}$ \\ Consensus on definition of REMISSION $\nearrow_{\text {LDA }}^{\text {Inactive }}$
}

Ankylosing Spondylosis (ASDAS) Disease Activity Score

1. Validated definition of low disease activity $<2.1$

2. Inactive Disease $<1.3$ (in active disease)

serves as a target for therapeutic strategy

or

3. Reduction by at least 1.1 during treatment

Selected cut-offs for disease activity states

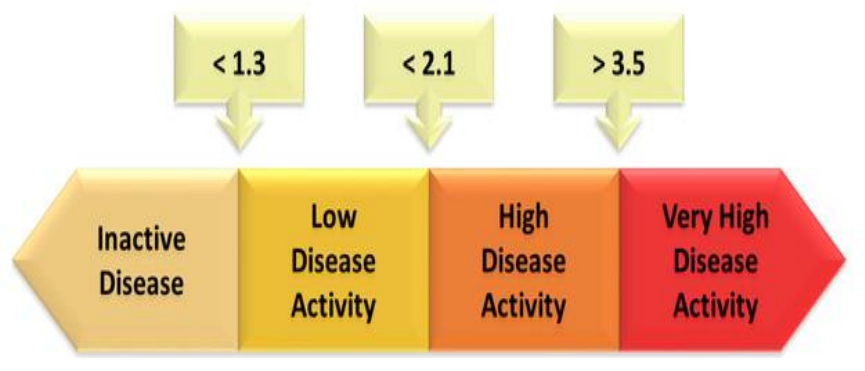

Selected cut-offs for improvement scores

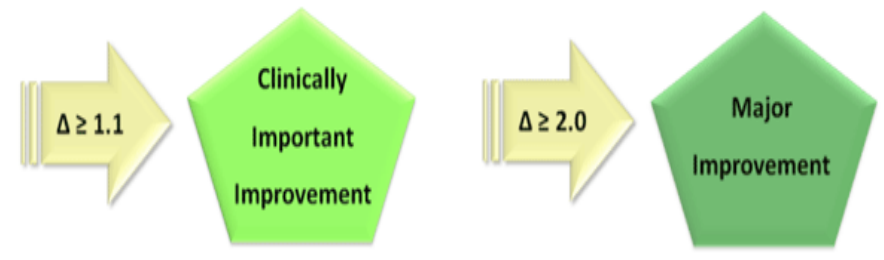

MOA of the Biologics ${ }^{20-23}$

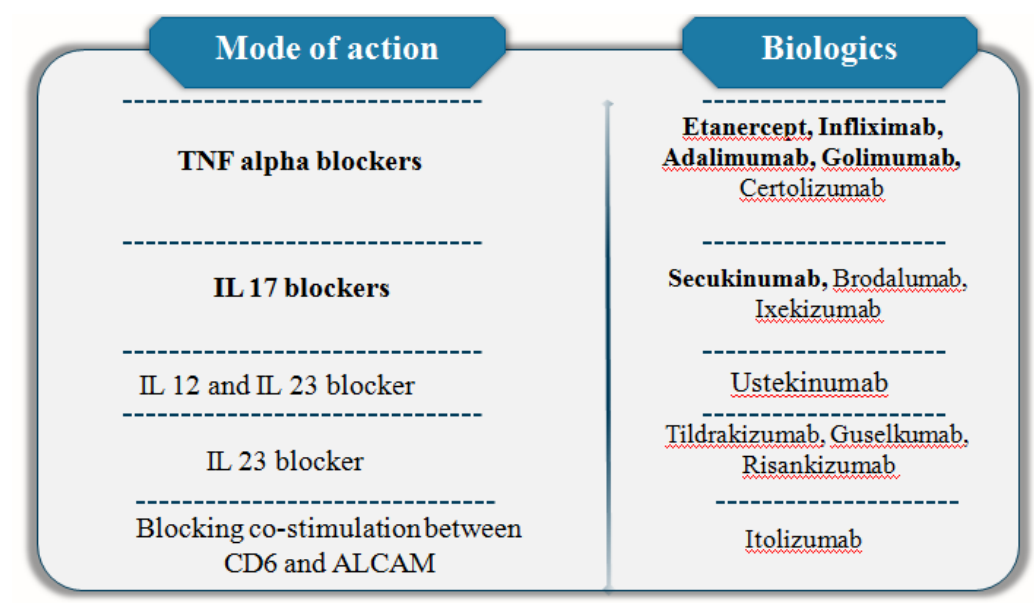




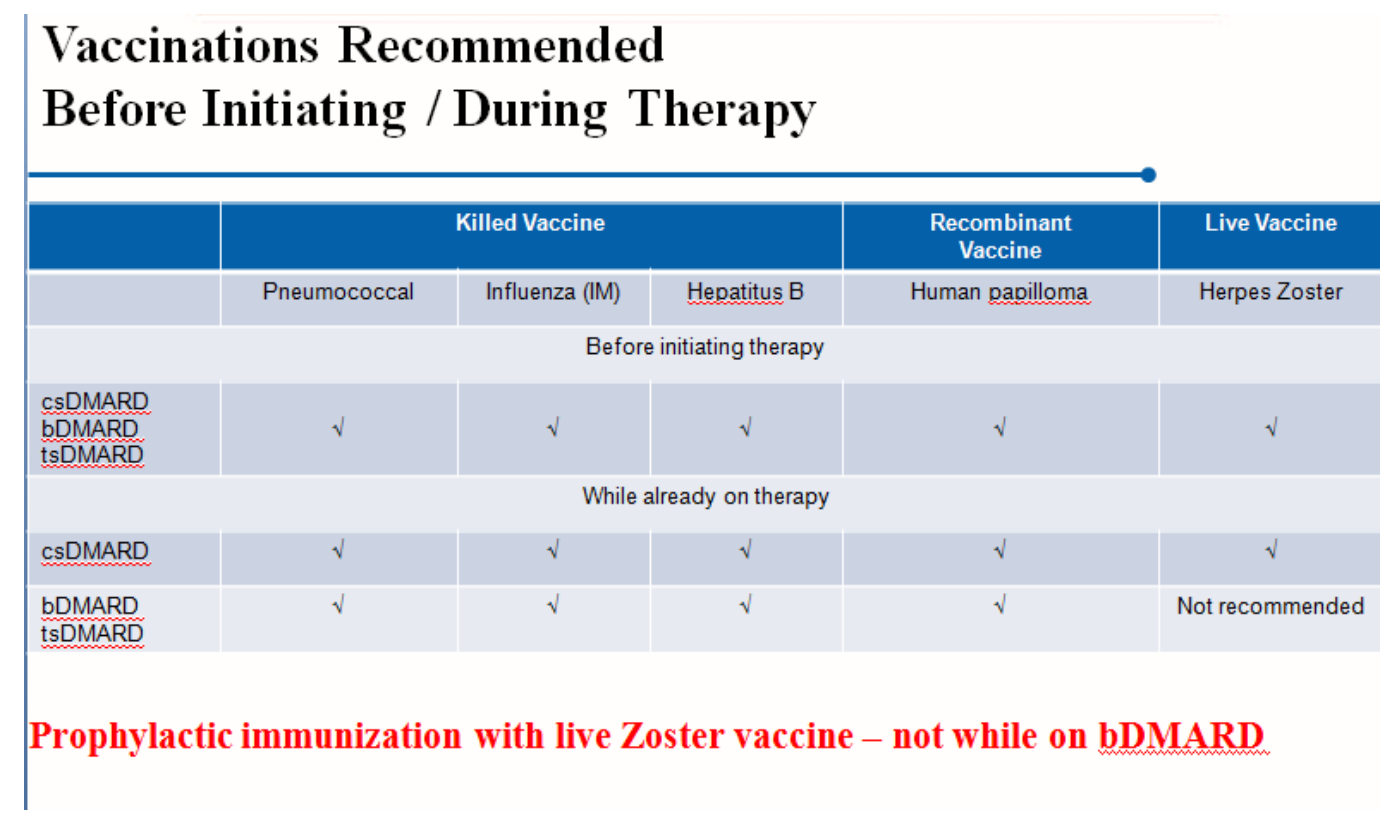

Recommendation for use of biologic therapy in perioperative period for elective surgery ${ }^{24}$

TNF-a antagonists should be discontinued at least 4 half lives prior to major surgery

\author{
2 weeks for Etanercept \\ 6-8 weeks for Adalimumab \\ 4-6 weeks for Infliximab
}

It can be restarted post operatively if there is evidence of no infection and wound healing is satisfactory

Effect on Structural Progression ${ }^{25}$

Do anti-TNF therapy reduce progression in AS?

Adults with established AS on anti-TNF therapy produced mixed results but have not shown a clear reduction in spinal radiographic progression when compared to historical cohorts never treated with anti-TNF 
Clinical evidence with Secukinumab: Statistical analyses ${ }^{8}$
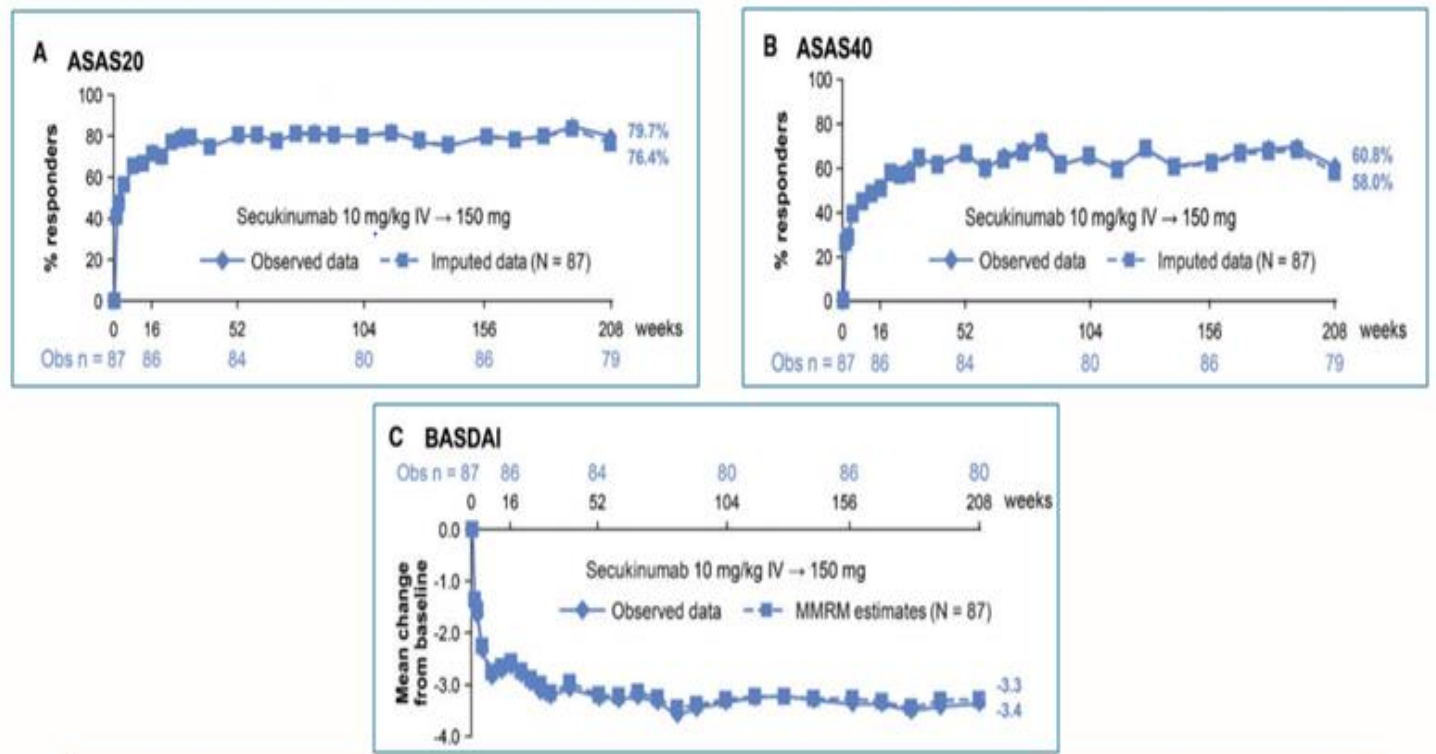

Secukinumab $150 \mathrm{mg}$ provided sustained efficacy across other clinical endpoints including BASDAI, with consistent findings for observed and imputed analyses

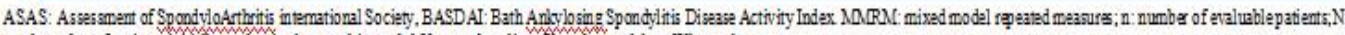
total number of patient mitraly yandomized to gevikinumab $150 \mathrm{mg}$ at baseline; Obs: Observed dat; Wh reek.

Clinical evidence with Secukinumab:Clinical efficacy and end results ${ }^{8}$

Cumulative probability plot of 4 years progression for mSASSS

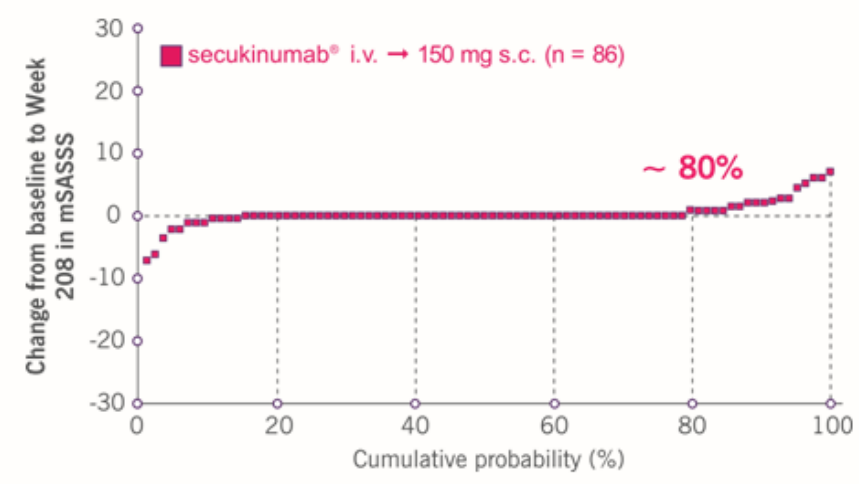

\section{$80 \%$ patients showed no progression of structural damage over 4 years}

mSASSS: modifiad Stoke Ankylosing Spondylitis Spine Score 


\section{Clinical evidence with Secukinumab ${ }^{8}$}

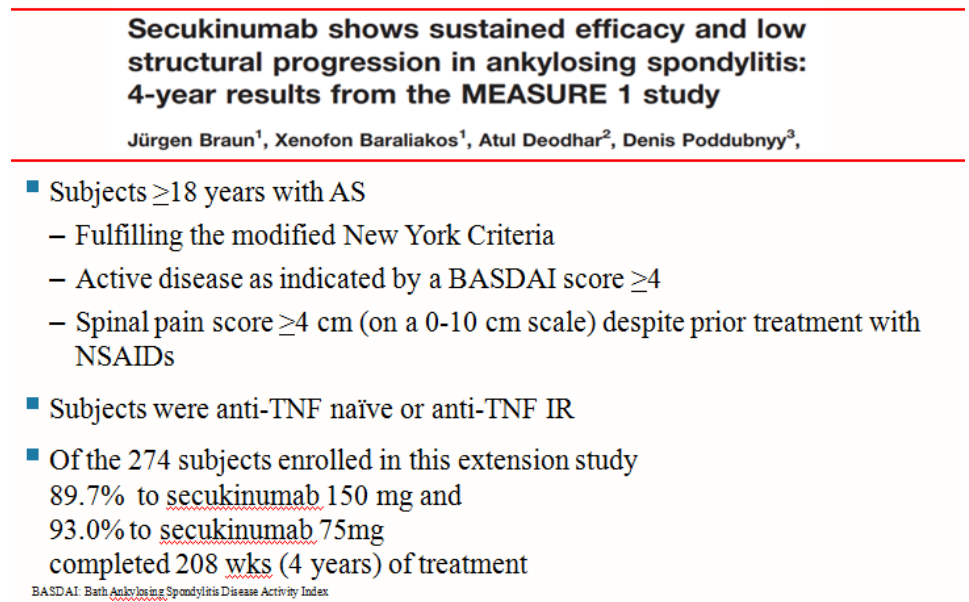

\section{Secukinumab Indian data from the fixture trial on Indian population ${ }^{26}$}

Incidences of AEs similar across all groups

\begin{tabular}{|c|}
\hline $\begin{array}{c}\text { Common AEs during } \\
\text { induction period }\end{array}$ \\
\hline Diarrhea (4.0\%) \\
Asthenia $(2.7 \%)$ \\
Pyrexia (2.7\%)
\end{tabular}

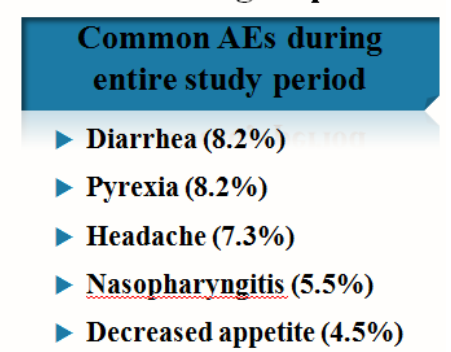

\section{No TB case reported}

\section{Traditional DMARDs}

In developing world, where cost is a constraint, rheumatologists must first initiate treatment with csDMARDs (the traditional) such as sulfasalazine and methotrexate. These medications should be used in higher dosage to achieve improvement in peripheral spondyloarthropathy and also to some advantage in axial spondyloarthropathy. In clinical practice, most widely used traditional DMARDs are having different levels of evidence-

Methotrexate - B level

Sulfasalazine - A level

Leflunomide - A level

Cycolosporine - B level

Efficacy of these agents in inhibiting joint erosions is not assessed in controlled studies and their effectiveness in controlling enthesitis and dactylitis is controversial. It is recommended to use them following biologic therapy whenever cost is a constraint or from the very beginning in higher dosage.

Sulfasalazine even otherwise, has potent antiinflammatory effect and for this reason of its behavior as NSAID, it is recommended for use even in axial SpA and definitely in peripheral SpA.

\section{References}

1. Poddubnyy D. Axial spondyloarthritis: is there a treatment of choice? Ther Adv Musculoskelet Dis 2013;5(1):45-54.

2. Ruben BV. The assessment of the spondyloarthritis international society concept and criteria for the classification of axial spondyloarthritis and peripheral spondyloarthritis: A critical appraisal for the pediatric rheumatologist, Pediatric Rheumatol, 2012;10:14.

3. Rudwaleit M. Ann Rheum Dis 2009;68:777-83.

4. Sieper J. Axial spondyloarthritis Article number: 15013 doi:10.1038/nrdp.2015.13

5. Khmelinskii N. The Role of Imaging in Diagnosing Axial Spondyloarthritis. Front Med 2018;5:106. doi: 10.3389/fmed.2018.00106.

6. Sari I. Radiographic Progression in Ankylosing Spondylitis: From Prognostication to Disease Modification. Curr Rheumatol Rep 2018;20:82.

7. Gerriets V. Tumor Necrosis Factor (TNF) Inhibitors; February 19, 2019.

8. Braun J. Secukinumab shows sustained efficacy and low structural progression in ankylosing spondylitis: 4-year results from the MEASURE 1 study. Rheumatol 2018 doi:10.1093/rheumatology/key375

9. Blair HA, Secukinumab. A Review in Ankylosing Spondylitis. Drug 2019;79(4):433-43.

10. V Bruner, M Atteno et al. Biological therapies for spondyloarthritis. Ther Adv Musculoskel Dis 2014;6(3):92101. 
11. https://nass.co.uk/wp-content/uploads/resources/Guide-toBiologic-Therapy.pdf

12. 2019 Update of the American College of Rheumatology/Spondylitis Association of America/Spondyloarthritis Research

13. https://www.enbrel.com/hcp/dosing-and-administration

14. https://exemptia.com/rheumatology.html

15. https://www.remicadehcp.com/ankylosingspondylitis/infusion-instructions/instructions-for-use/dosingguide.html

16. https://www.cosentyxhcp.com/ankylosingspondylitis/dosing/prescribing/

17. https://www.simponihcp.com/rheumatoid-arthritis/dosing

18. Baraliakos X. Which spinal lesions are associated with new bone formation in patients with ankylosing spondylitis treated with anti-TNF agents? A long-term observational study using MRI and conventional radiography. Ann Rheum Dis 2014;73:1819-25.

19. Marzo-Ortega H. Defining the target: clinical aims in axial spondyloarthritis. Rheumatol (Oxford) 2018;57(Suppl 6):vi18vi22. doi: 10.1093/rheumatology/key176

20. Bruner V. Biological therapies for spondyloarthritis. Ther $A d v$ Musculoskelet Dis 2014;6(3):92-101.
21. Paine A. Targeting the IL-23/IL-17 Axis in Axial Spondyloarthritis. Curr Opin Rheumatol 2016;28(4):359-67.

22. Torgutalp M. Emerging treatment options for spondyloarthritis. Best Pract Res Clin Rheumatol 2018;32(3):472-84.

23. Aira LE. Immunological evaluation of rheumatoid arthritis patients treated with itolizumab, MAbs. 2016;8(1):187-95. (ACLAM- activated Leucocyte-cell adhesion molecule).

24. Rajagopalan M. Biologics use in Indian psoriasis patients. Indian Dermatol Online J 2016;7(6):489-97.

25. Bray TJP. Sacroiliac Joint Ankylosis in Young Spondyloarthritis Patients Receiving Biologic Therapy: Observation of Serial MRI scans. Arthritis Rheumatol 2019;71(4):594-8. doi:10.1002/art.40750.

26. Bhat RM. Indian Dermatol Online J 2017;8:16-24.

How to cite this article: Jha SS. Spondyloarthropathy: A critical management analysis. Int J Orthop Rheumatol 2019;5(2):42-54. 